Article

\title{
Evaluating Art Licensing for Digital Archives Using Fuzzy Integral
}

\author{
Yu-Jing Chiu *, Yi-Chung Hu@, Jia-Jen Du, Chung-Wei Li and Yen-Wei Ken \\ Department of Business Administration, Chung Yuan Christian University, Chung Li District, \\ Taoyuan City 32023, Taiwan; ychu@cycu.edu.tw (Y.-C.H.); smdo03@yahoo.com.tw (J.-J.D.); \\ research.cwli@gmail.com (C.-W.L.); gyw83@yahoo.com.tw (Y.-W.K.) \\ * Correspondence: yujing@cycu.edu.tw; Tel.: +886-3-265-5127
}

Received: 29 October 2020; Accepted: 9 December 2020; Published: 11 December 2020

check for updates

\begin{abstract}
Determining how to evaluate the art licensing model is a complex multi-criteria decision making (MCDM) problem. This study explores the critical factors influencing art licensing in the art and creative industry because this industry has potential contributions to a high value-added cultural economy in Taiwan. Due to the high cultural value of the National Palace Museum and the uniqueness of its cultural relics, this study takes it as an empirical case. The decision hierarchy is constructed based on a literature review and expert interviews. Furthermore, we used the fuzzy integral to calculate the weights and overall performance of the three licensing models. The empirical results illustrate that both brand licensing and image licensing groups emphasized the aspect of market environment as the primary consideration for licensing model selection. In particular, respondents considered that the adoption of a brand licensing model could facilitate the achievement of better overall performance value. The reason is that brand licensing made the company's brand visible by imprinting the brand names of both the National Palace Museum and the company on products. This study can be used as reference model for the evaluation of art licensing by enterprises in the future.
\end{abstract}

Keywords: fuzzy integral; fuzzy measure; art licensing; the National Palace Museum

\section{Introduction}

In a fiercely competitive environment, companies not only need to demonstrate the functional value of their products, but also need to convey the emotional value of their products to customers. ABN-AMRO Bank uses licensed images of Van Gogh's art for its external wall decorations, credit card backdrops, and corporate giveaways, which tripled the number of credit cards it issued within three months of implementing this scheme. This demonstrated that the "aesthetic revenue" generated by art and culture is astonishing [1]. For modern people, life is not merely concerned with physical sustenance anymore. Instead, it has become focused on how to enrich the spirit [2]. Countries worldwide are committed to the development of the cultural and creative industries. Many creative products and services are marketed worldwide, thereby enabling the burgeoning of the creative economy [2]. In 2018, Taiwan's Cultural and Creative Industries have bloomed compared with the past two years. It shows that the digital transformation of the industry and the promotion of related cultural policies have achieved positive results in 2018. The total sales revenue of the industries was NT\$879.82 billion, reaching an increase of 5.22\%, growing at almost twice the rate of Taiwan's GDP in 2018. It shows that Taiwan's Cultural and Creative Industries have great potential to contribute to the Taiwanese economy [3]. With the continued development of Taiwan, its populace's demand for material goods will decrease, but their demand for experiential goods will increase [3]. Nowadays, enterprises in Taiwan are facing industrial transformation and should rely on creativity and related intellectual property to seek industrial breakthroughs. 
The application of digital technology and the accelerating popularity of the Internet and various electronic media have bolstered the digital preservation of artworks. In the case of the National Digital Archives Technology Program, the hope is to develop value-added application of art and culture through technology. Cultural and creative content has been extensively applied. However, the commercial applications of art and culture have certain challenges, particularly because the commercialization of cultural and creative content encounters the problem of intellectual property ownership and licensing. Thus, if operated through a management mechanism, intangible cultural and creative content can be used in various business platforms to create more economic value. Based on the commercial application of the digital collection of the National Palace Museum in Taiwan, this study will investigate how to enhance the "aesthetic competitiveness" of manufacturers through art licensing, with a view to creating high value-added "aesthetic revenue."

According to Hesmondhalgh [4], and Liu's [5] definitions of the cultural industry, the entire industrial chain of the cultural industry should be supported by many related companies. They would assist in the development of the core original art, and in the corresponding marketing and creative services. Cultural products or services not only symbolize the function and intangible artistic image of the product or service itself, but also denote emotional symbols that they represent more extensively. From cultural symbolism to the extension of ideas, public communication and cross-border integration can stimulate additional creativity and intellectual property. Although there is no specific international consensus on the definition of the term "cultural industry", the present norm is the British concept of creative industry, which represents a process of tapping into cultural resources and creativity. Taiwan adopts the term "cultural and creative industry" and defines it as "an industry that originates from creativity or cultural accumulation and has the potential to create wealth and employment opportunities and contribute to the improvement of the overall living environment through the formation and use of intellectual property" [6]. Wu suggests that the cultural and creative industries allow creative culture to integrate with business, which consequently transforms the social relationship between culture and people through the operation of market mechanisms $[7,8]$.

As the cultural and creative industries are emerging industries, relevant government measures and business models are inconclusive. It is therefore an important issue to construct a selection model for the commercial application of art licensing. The purpose of this study is to examine the factors that affect the promotion of cultural content for commercial use through art licensing and establish an evaluation model for art licensing, thereby assisting collection agencies' and manufacturers' uses of value-added content as an evaluation tool. The cultural and creative industries cover a wide range of areas and are defined differently across countries. Taiwan's cultural and creative industry uses the art licensing in the National Palace Museum as the leader in the industry. With an annual revenue of NT\$400 million and rich collections of cultural relics, it has become a catalyst in the development of the cultural and creative industries in Taiwan. Thus, to survey the value-added application of digital collection of cultural relics in commerce, the National Palace Museum was adopted as the research scope of this study and the manufacturers who had collaborated with the National Palace Museum were chosen as its subjects.

In the past, scholars have conducted qualitative research on the art licensing model and have performed case interviews or focus group interviews to learn about the licensing relationship between value-added manufacturers and the National Palace Museum. In this study, the experts' opinions on all criteria were collected over personal interviews. Due to the intrinsic ambiguity of human language, their preferences and opinions are not easy to be quantified into accurate numerical values. Fuzzy theory is a proven method for collating experts' decisions and producing dependable outcomes. This study uses fuzzy set theory to deal with the language of humans via devising an investigation using the scales of triangular fuzzy numbers.

Therefore, this study aims to develop a more complete evaluation model for art licensing by integrating a literature review and expert interviews. After studying the relative importance attached to three licensing models, aspects, and criteria in the National Palace Museum in different licensing 
groups, we compared the results with performance values to identify the considerations of value-added manufacturers under different licensing models, which can be used as the basis of consideration for future value-added manufacturers. We hope that the efforts of this study will be instructive in the development of art licensing.

The rest of this paper is structured as follows. In Section 2, we review existing literature to identify the aspects and criteria influencing the evaluation of art licensing. In Section 3, the research methodology is described. We illustrate the approach by an empirical case in Taiwan in Section 4. Finally, the discussion and conclusions are presented in Sections 5 and 6.

\section{Literature Review}

\subsection{Value-Added Application of Digital Archive}

The National Palace Museum has recently fostered the development of digital archives as a value-added service. Since the National Palace Museum has an unparalleled collection of Chinese treasures and cultural relics, its value-added products are highly lucrative. The relics can be applied as multiple derivative value-added products. For instance, the image of the same painting can be made into various gifts and CDs. These gifts or publications can also be internationalized and intellectual property protection can be applied for. Moreover, content is the most vital aspect of a knowledge-based economy. The National Palace Museum possesses the most valuable cultural relics, which lay a favorable foundation for the development of remarkable digital content industries.

The digital archive covers a vast range of materials, including culture, music, art, and animals and plants, with the purpose of ensuring the availability, permanence, and intellectual integration of all digital data [9]. Digital archiving is the use of technology to digitize valuable content that can be preserved and reproduced in the form of digital files for further application [10]. The digital archiving process, in this case, involves the creation of digital images and documents for cultural relics, including photography, scanning, color correction, and metadata design. It provides a catalog query system for cultural relics, which allows Chinese and foreign viewers to appreciate enormous Chinese treasures and serves as a basis for digital museums, digital learning, and service development in the content industry [11]. In terms of the production process, "digital archive" refers to digital processing (photography, full-text input, and scanning) and metadata descriptions stored in the form of digital files [12].

Overall, the contents of digital archives are not limited to art and culture, but also extend to the assets of human civilization. The records and legacies of human civilization are stored in digital archives using a variety of digital methods, such as digital imaging and 3D scanning, and are further integrated with added value to create greater value and more applications for these items.

Digital archives can be used in two ways. The first is for inspiration and the other is for the application of materials [13]. It is believed that the archive unit not only digitizes the collection items, but also incorporates the investigation and explanation of the collection items into the digital archive database. In this way, users can acquire a deeper understanding of the materials and appropriately use the images of digitally collected cultural relics, thereby stimulating more creative ideas. For the industrialization of culture, the application of materials can accelerate the direct commercialization of manufacturers to face the market.

Digital archives include materials with high cultural value. Through constant resource reorganization and innovation, the digital content can be used more effectively, its value can be maximized, and it can facilitate the development of the digital content industry. Moreover, the market-based revenue is used to make the industry sustainable and the business model of digital archives is divided into five categories [14], as shown in Table 1. 
Table 1. Five business models of digital archives.

\begin{tabular}{cc}
\hline Business Model & Description \\
\hline Value-added cultural products & $\begin{array}{c}\text { Digitally collected objects are value-added and transformed into } \\
\text { products that the general public has access to, such as household } \\
\text { goods (e.g., art reproductions, porcelain, and textiles) and travel. }\end{array}$ \\
\hline Digital technology software and services & $\begin{array}{c}\text { Technologies and services required for digital object } \\
\text { management and productization include copyright collection, } \\
\text { licensing services, scanning software and tools, and digitization } \\
\text { services for physical products. }\end{array}$ \\
Value-added industrial database & $\begin{array}{c}\text { To provide digitally collected objects, to cut and add value to } \\
\text { digitally collected materials, and to serve as a source of } \\
\text { inspiration for product design in the leisure and entertainment } \\
\text { industry, digital learning industry, and value-added cultural } \\
\text { industry, such as digital learning, animation and game scripts, } \\
\text { art and design applications. }\end{array}$ \\
Additional content service & $\begin{array}{c}\text { To embed value-added, digitally collected content in digital } \\
\text { products in the form of media channels and application } \\
\text { platforms, such as i-mode art impression gallery and wallpaper } \\
\text { download services in the telecommunications industry. }\end{array}$ \\
\hline Integrated product & $\begin{array}{c}\text { To make digitally collected objects available in an integrated } \\
\text { form for research, education, and public use, such as the Shells } \\
\text { and Humanities Database. }\end{array}$ \\
\hline
\end{tabular}

Source: Data from [14] after reconstruction.

Culture is a type of intangible knowledge and creativity is the crystallization of thoughts. Therefore, the results created by art creators are protected by copyright. Additionally, the licensing relationship that is established between art creators and users and the development of the cultural and creative industries depend on the protection system for intellectual property rights. The system persuades investors and developers to invest in the development of creative goods and cultural services, thereby bolstering the development of the cultural and creative industries.

\subsection{Overview on Art Licensing Market and Types in the National Palace Museum}

Starting in Europe and the United States, the business of art licensing has a history that spans over 20 years in the West. However, it is an emerging industry in Asia. In 1997, Artkey, the first company that specialized in art licensing services in Taiwan, was founded. Guo Yicheng, the CEO of the company, holds the belief that art licensing mainly involves the intellectual property rights of artworks. Through the licensing method, the intellectual property rights of works of creators are used for commercial purposes, such as reproduction, public display, alteration, and rental.

Fondo suggests that art licensing is a process by which a licensee (e.g., a manufacturer) and a licensor (e.g., a creator) enter into a contract to apply the copyright and intangible assets of an artwork to a specific product in a specific geographical area and at a specific time [15]. In this process, the licensor can receive royalties from the sales of licensed products per unit. Thus, the use of art licensing allows the dissemination and circulation of creative works through the licensing mechanism and raises their economic and cultural value.

Bruno indicates in the book Arts $\mathcal{E}$ Economics that art and economy can operate synergistically and exist interdependently [16]. Without a sound economic foundation, art cannot survive; conversely, without creativity, the economy cannot flourish. Consequently, art must be used in conjunction with the economy in order for it to spill over into the overall economic environment.

The main reason why the traditional art industry has not been able to develop economies of scale is that only a single original work of art is available. With today's digital technology, the reproduction of artworks through digital technology allows art and cultural works that used to be owned by the 
wealthy to be licensed to the digital content industry and the cultural and creative industries through the means of art licensing.

The National Palace Museum, a model for art licensing in Taiwan, has recently promoted the content of its digital archives and the cultural and creative industries to the international market. For instance, the museum put on an exhibition at the world's largest licensing marketplace-the New York Licensing International Show. In this way, the National Palace Museum conveys taste, aesthetics, and culture in a new manner through the application of its value-added digital archive.

Chou argues that museums can produce new derivative works through art licensing, regain the protection of intellectual property rights conferred by law, and enforce these new intellectual property rights to generate more added value through effective management and administration [17]. Museums can operate in a sustained manner because of the proceeds of licensing.

There are three types of art licensing in the National Palace Museum, namely commissioned production, brand licensing, and image licensing, as shown in Table 2.

Table 2. Types of art licensing in the National Palace Museum.

\begin{tabular}{|c|c|c|c|}
\hline Type of Licensing & Commissioned Production & Brand Licensing & Image Licensing \\
\hline Definition & $\begin{array}{l}\text { The National Palace } \\
\text { Museum commissions } \\
\text { manufacturers to produce } \\
\text { cultural derivatives or } \\
\text { develop technologies. }\end{array}$ & $\begin{array}{l}\text { Manufacturers pay to } \\
\text { rent registered trademark } \\
\text { of the National Palace } \\
\text { Museum and some of its } \\
\text { images, and the products } \\
\text { are imprinted with the } \\
\text { trademarks of the } \\
\text { National Palace Museum } \\
\text { and the manufacturer. }\end{array}$ & $\begin{array}{l}\text { Photos, negatives, or } \\
\text { electronic files of books } \\
\text { or cultural relics in the } \\
\text { National Palace Museum } \\
\text { are used for commercial } \\
\text { or non-commercial } \\
\text { purposes. Only the } \\
\text { images are licensed. }\end{array}$ \\
\hline
\end{tabular}

\begin{tabular}{|c|c|c|c|}
\hline Property ownership & $\begin{array}{c}\text { The National Palace } \\
\text { Museum commissions the } \\
\text { production or design of } \\
\text { goods, but the property right } \\
\text { and design copyright belong } \\
\text { to the National Palace } \\
\text { Museum. }\end{array}$ & $\begin{array}{l}\text { Belongs to the } \\
\text { commissioned } \\
\text { manufacturer. }\end{array}$ & $\begin{array}{l}\text { Property copyright and } \\
\text { design copyright belong } \\
\text { to the commissioned } \\
\text { manufacturer. }\end{array}$ \\
\hline Licensing channel & $\begin{array}{l}\text { Sold at the Souvenir Shop of } \\
\text { the National Palace Museum } \\
\text { and contracted retailers, i.e., } \\
\text { the NPM's own channels. }\end{array}$ & $\begin{array}{l}\text { The NPM's channels } \\
\text { may be the licensee's } \\
\text { marketing channel. }\end{array}$ & Licensee's channel \\
\hline
\end{tabular}

Data source: Data from [1] after reconstruction.

From the overview on the concept of art licensing, the purpose of art licensing is to generate economic value for art and culture, which is a key economic activity in the cultural and creative industries. The digital archive of the National Palace Museum contains abundant artistic and cultural content, which not only provides cultural and creative content through licensing, but also plays a 
role in design planning, marketing and publicity, or channeling, thus exerting an enormous influence within the cultural and creative industries. Therefore, this study took the three licensing modes of the National Palace Museum as its research scope.

\subsection{The Applications of MCDM and Fuzzy Integral}

In an increasingly complex social environment, there may be omissions in making decisions by considering only simple metrics. Therefore, in an environment involving broad-based and multi-objective decision-making, where there are many conflicting objectives that have to be weighed against trade-offs and subjective value judgements, traditional single-criteria assessment methods, such as cost-benefit analysis, may not be appropriate to address.

Therefore, the multi-criteria decision-making method (Multiple Criteria Decision-Making, MCDM) is suitable for complex decision-making issues. Chiu [18] uses the Analytic Hierarchy Process (AHP) method to find the key success factors of museums in artistic authorization. The results show that the most important resources are organizational capacity, followed by intangible assets. Tang et al. [19] use fuzzy multi-criteria decision-making to measure e-commerce market strategy and it is concluded that this method is quite appropriate. Furthermore, the quality of service in the aviation industry is evaluated by fuzzy hierarchical analysis. The weight between attributes is obtained by hierarchical analysis, and TOPSIS(Technique for Order Preference by Similarity to an Ideal Solution) is used to evaluate the preference of the scheme [20].

The fuzzy integral of non-addition type is very suitable for the treatment of subjective evaluation or uncertainty, and fuzzy integral analysis has been widely used in many fields. The applicability of the proposed fuzzy similarity-based method to movie recommendation is examined. The results demonstrate that the generalization ability of the multi-criteria neighborhood method using the proposed fuzzy similarity measure performs well in comparison to that using the additive similarity measure on the basis of grey relational analysis (GRA). Yildiz and Yayla [21] apply the fuzzy TOPSIS and generalized Choquet integral methods to select the best supplier in a firm in the automotive industry of Turkey. Tseng and Chiu [22] combines the Choquet integral and the stated preference method to propose the hierarchical fuzzy integral stated preference (HFISP) method, and then analyze the narrowband service users' preferences for broadband service. The results demonstrate that the hierarchical fuzzy integral stated preference method performs better than the partitioned fuzzy integral multi-nomial logit (PFIMNL) model. Lu et al. [23] apply the integrated fuzzy MADM(Multiple Attribute Decision Making) approach to estimate sustainable development performance in the electrical wire and cable industry. The proposed method can provide guidance to prioritize the influential factors in the improvement strategies for achieving the aspired value of sustainable development performance.

In summary, the use of multi-criteria decision-making methods and fuzzy integral can systematically deal with complex decision-making issues, and is also widely used in many fields, but less used in the discussion of cultural and creative industries, so this study uses fuzzy integral for the selection of artistic licensing models.

\section{Research Methods}

The Fuzzy theory was applied to the licensing model for art and culture. Moreover, the use of fuzzy set theory allows the affiliation of each element of a set to be expressed as any value between 0 and 1, which extends binary logic to multi-value logic. At the same time, the general multi-criterion evaluation method is useful, especially when there are many complex problems in the real world and which do not fit into an additive linear model, because each evaluation aspect is somewhat correlated with the others and does not conform to the additive hypothesis as presented in the research. The method and questionnaire design were shown as follows. 


\subsection{Fuzzy Theory}

Fuzzy theory was developed by Lotfi Zadeh, whose famous article, "Fuzzy Sets," was published in an academic journal in 1965. A fuzzy set refers to the extent to which the elements of the set belong to the set, which is expressed as a value between 0 and 1 [24]. The past set was a binary logical system that allowed the elements to be clearly identified as belonging to a set, which is a common crisp set in mathematics, a definite set. "Definite" means that a clear judgment can be made between "yes" and "no." There are some things that we can clearly distinguish, such as gender; however, it is often difficult to make a clear distinction between most things and their semantic expressions. The theory of fuzzy set, similar to the way people think, allows the affiliation of each element of a set to be expressed as any value between 0 and 1 , which extends binary logic to multi-valued logic.

\subsection{Fuzzy Measure and Fuzzy Integral}

\subsubsection{Fuzzy Measure}

The fuzzy measure is a non-additive measure that represents the relative importance of the property set to problems, and is therefore called the importance measure. Due to its non-additive nature, the fuzzy measure is usually combined with the fuzzy integral to obtain the overall performance value of schemes.

\subsubsection{Fuzzy Integral}

In a general multi-criteria evaluation method, when considering evaluation problems for multiple aspects, it is necessary to assume in advance that the aspects are uncorrelated and adopt the additive method as a basis for assessment. A common method is "weighted average," which simplifies the question but ignores the interactions between aspects when assessing the options. However, there are many complex problems in the real world that do not fit into an additive linear model, because each assessment aspect is somewhat correlated with each other and does not conform to the additive assumption [25].

The fuzzy integral was first proposed by Prof. Sugeno in 1974 as a non-additive method because it can be applied to situations in which there is a correlation between assessment criteria and it is suitable for dealing with subjective value judgments [25].

Among these functions, the fuzzy measures are usually taken into account. Let $P(X)$ denote the power set of $X=\left\{x_{1}, x_{2}, . ., x_{n}\right\}$. Then, $(X, P(X))$ is a measurable space. A set function satisfying $\mu$ : $P(X) \rightarrow[0,1]$ is called a fuzzy measure [24,26]. Since the attributes are finite, the continuity property on $\mu$ may be omitted. The fuzzy measure with the monotonicity assumption considers the interaction among attributes towards the objective attribute by replacing the usual additive property with the monotone property [27].

1. $\mu(\phi)=0, \mu(X)=1$ (boundary conditions);

2. For $\forall R, S \in P(X)$, if $R \subset S$, then $\mu(R) \leq \mu(S)$ (monotonicity);

3. For every sequence of subsets of $X$, if either $R_{1} \subseteq R_{2} \subseteq \cdots$ or $R_{1} \supseteq R_{2} \supseteq \cdots$, then $\lim _{i \rightarrow \infty} g\left(R_{i}\right)=$ $g\left(\lim _{i \rightarrow \infty} R_{i}\right)$ (continuity).

Let $E_{j}=\left\{x_{j}, x_{j+1}, \ldots, x_{n}\right\}(1 \leq j \leq n)$. The interaction among the attributes in $E_{j}$ can be described by employing $\mu\left(E_{j}\right)$ to express the degree of importance of $E_{j}$. Let $\mu_{j}$ denote $\mu\left(\left\{x_{j}\right\}\right)$, which is called a fuzzy density. The nonadditivity of $\mu$ means that $\mu\left(E_{j}\right)$ may be smaller or greater than $\mu_{j}+\mu_{j+1}$ $+\ldots+\mu_{n}$, expressing thus an interaction among $x_{j}, x_{j+1}, \ldots, x_{n}$ [28]. In practice, $\mu$ is used as an importance measure [29]. $\mu\left(E_{j}\right)$ can be also employed to express the discriminatory power of $E_{j}$. Graphical representation of the Choquet fuzzy integral is shown in Figure 1. 


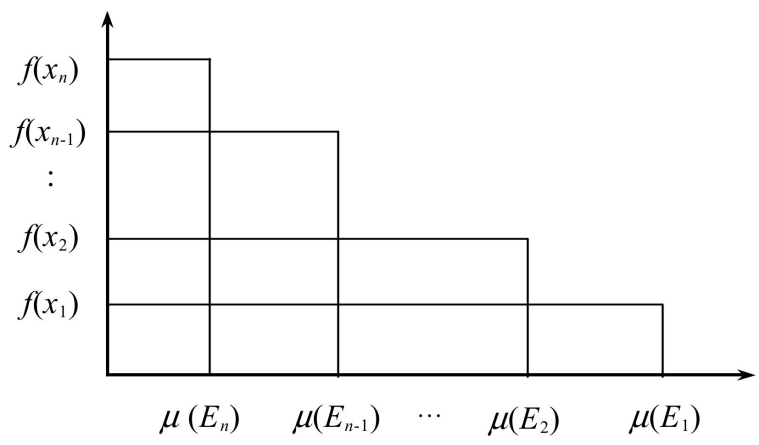

Figure 1. Graphical representation of the Choquet fuzzy integral.

Among the various fuzzy measures, the $\lambda$-fuzzy measure has been suggested for computing the fuzzy integral $[29,30]$ and is a convenient class of fuzzy measures often employed by users [30]. For all $R, S \in P(X)$ with $R \cap S=\phi, \mu$ is the so-called $\lambda$-fuzzy measure satisfying the following property [31]:

$$
\mu(R \cup S)=\mu(R)+\mu(S)+\lambda \mu(R) \mu(S), \lambda \in(-1, \infty)
$$

For the interaction between $R$ and $S$, if $\lambda>0$, then there is a multiplicative effect between $R$ and $S$; if $\lambda<0$, then there is a substitutive effect between $R$ and $S$. If $\lambda=0$, then $R$ and $S$ are noninteractive such that $\mu(R \cup S)=\mu(R)+\mu(S)$. After determining $\mu_{1}, \mu_{2}, \ldots, \mu_{n}, \lambda$ can be uniquely determined by $\mu(X)=1$. Then, $\mu\left(E_{j}\right)$ can be computed by

$$
\mu\left(E_{j}\right)=\mu_{j}+\mu\left(E_{j}+1\right)+\lambda \mu_{j} \mu\left(E_{j}+1\right)=\frac{1}{\lambda}\left[\prod_{i=j . n}\left(1+\lambda \mu_{i}\right)-1\right]
$$

It should be noted that if $\sum_{i=1}^{n} \mu_{i}>1$, then $-1<\lambda<0$; if $\sum_{i=1}^{n} \mu_{i}<1$, then $\lambda>0$; if $\sum_{i=1}^{n} \mu_{i}=1$, then $\lambda=0$. For instance, if $n=2$, then $\mu(X)=\mu_{1}+\mu_{2}+\lambda \mu_{1} \mu_{2}=1$ holds. It is obvious that $\lambda>0$ When $\mu_{1}+\mu_{2}<1$.

\subsection{Questionnaire Design and Data Collection}

This paper applies the proposed method in Taiwanese National Palace Museum as an empirical study. All information was collected by interviewing experts with rich experience in this industry.

The two-stage questionnaire consisting of two stages was designed by collecting and sorting the literature and interviewing experts to screen important aspects and criteria. The main purpose of the first-stage questionnaire design was to establish the evaluation model of this study. Then, based on the findings from the first stage, the design of the second-stage questionnaire was composed of the following four parts.

Stage 1: The main purpose of the first-stage questionnaire design was to establish the model of this study over personal interviews. Therefore, experts evaluated the "suitability" of each evaluation item and provided corrective suggestions to the researchers in the blank space. The evaluation scale included four items: "strongly agree," "agree," "disagree," and "strongly disagree," and experts and scholars checked the most appropriate option in accordance with their views. 
Example 1:

\begin{tabular}{ccccc}
\hline Evaluation Aspect & $\begin{array}{c}\text { Strongly } \\
\text { Agree }\end{array}$ & Agree & Disagree & $\begin{array}{c}\text { Strongly } \\
\text { Disagree }\end{array}$ \\
\hline Market environment & & & \\
\hline Products & & & \\
\hline $\begin{array}{c}\text { Organization capability } \\
\text { of value-added } \\
\text { manufacturers }\end{array}$ & & & \\
\hline
\end{tabular}

Stage 2: The aspects and criteria of the second-stage questionnaire were based on the findings of the first-stage questionnaire. The design of the second-stage questionnaire was composed of the following four parts.

(1) Definitions of aspects and criteria: A list summarized the definitions of the measurement aspects of the questionnaire for the convenience of the respondents.

(2) Evaluation of relative importance: For each aspect and criterion, the interviewee was asked to rate it ranging from 1 to 10 points. A higher score indicated higher importance, whereas a lower score indicated lower importance.

Example 2:

\begin{tabular}{|c|c|c|c|c|c|c|c|c|c|c|}
\hline \multirow{2}{*}{ Aspect } & \multicolumn{10}{|c|}{ Low $\leftarrow$ Importance $\rightarrow$ High } \\
\hline & 1 & 2 & 3 & 4 & 5 & 6 & 7 & 8 & 9 & 10 \\
\hline $\begin{array}{c}\text { Market environment } \\
\text { Value added to products } \\
\text { Organization capability of value-added manufacturers }\end{array}$ & & & & & & & & & & \\
\hline
\end{tabular}

(3) Fuzzy semantic scale: Using the affiliation function of fuzzy theory to approximate the thinking logic of the respondents, they were asked rate their subjective perceptions on a scale of 1-100 points, ranging from "unsatisfactory" (0 points) to "highly satisfactory" (100 points).

Example 3:

\begin{tabular}{ccccc}
\hline Highly Unsatisfactory & Unsatisfactory & Average & Satisfactory & Highly Satisfactory \\
\hline 0 & 30 & 60 & 85 & 100 \\
\hline
\end{tabular}

(4) Performance value evaluation of the three licensing models: The respondents were asked to rate their experience on a five-point scale under each aspect and criterion.

The second stage of the questionnaire involved selecting several manufacturers that had cooperated with the National Palace Museum in art licensing and distributing the questionnaire. The target audiences of the questionnaire were middle and senior managers such as project managers and product marketing managers.

\section{The Case Study}

The National Palace Museum is a leader in Taiwan's cultural and creative industries, generating an annual revenue of NT $\$ 400$ million through artistic licensing on a rich collection of cultural relics. Therefore, this study chose the National Palace Museum as the case of research, and the manufacturers who have cooperated with the Palace Museum as the main object of research and investigation, to explore its digital archives of cultural relics in the commercial value-added application. 
A research structure was initially set up by literature review, and then it was reconstructed by three qualified experts. In order to ensure that the research structure was in line with the current situation of the industry, this research interviewed three experts. The three experts are Professor Hsia, Normal University; Prof. Lin, Chung Yuan University; and Su, general manager of an art center. They are outstanding in professional and practical operation in the field of art licensing and digital archiving. We established relevant aspects and criteria that affect the licensing model of art and culture. Figure 2 shows that after reviewing the literature and referencing the opinions of the three experts, we summarized the definitions of aspects and criteria in Table 3.

Then, we analyzed the data collected from the questionnaires and calculated the overall performance value. In particular, the aspects, criteria, and the overall performance value that are emphasized under different licensing models were sought to be examined.

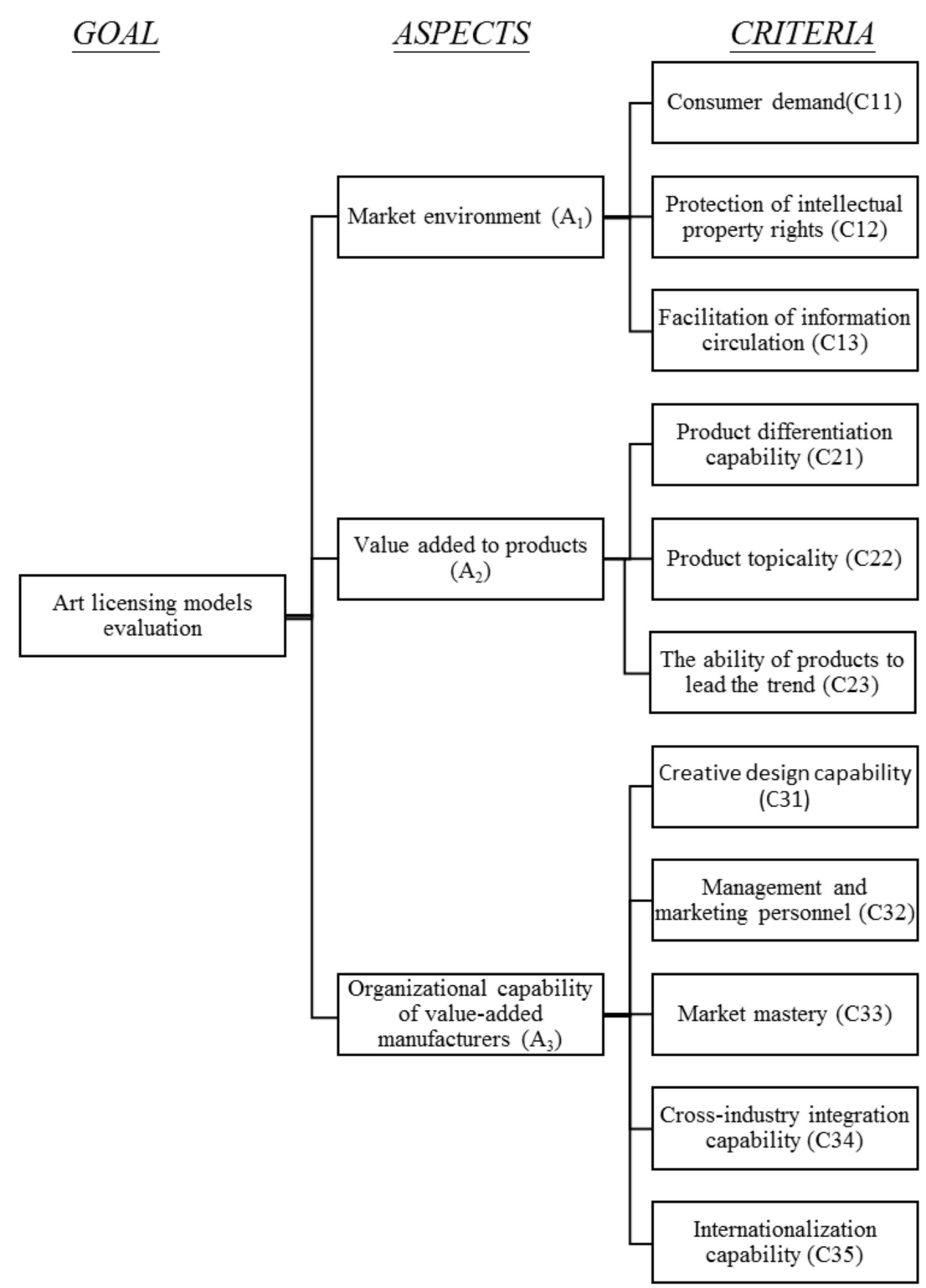

Figure 2. Decision hierarchy of art licensing models. 
Table 3. Definitions of aspects and criteria.

\begin{tabular}{|c|c|c|}
\hline Aspects and Criteria & Description & Reference \\
\hline Market environment (A1) & The overall market environment faced. & Experts \\
\hline Consumer demand (C11) & $\begin{array}{l}\text { The degree of acceptance of art-licensed goods by } \\
\text { domestic consumers (a higher acceptance indicates } \\
\text { higher commercial value). }\end{array}$ & Caves [32] \\
\hline $\begin{array}{l}\text { Protection of intellectual property } \\
\text { rights }(\mathrm{C} 12)\end{array}$ & $\begin{array}{l}\text { The extent to which the Act protects the rights of } \\
\text { both parties to an artistic license. }\end{array}$ & $\begin{array}{l}\text { Chiu [18], Shang [33], \& } \\
\text { Hsiang et al. [14] }\end{array}$ \\
\hline $\begin{array}{l}\text { Facilitation of information } \\
\text { circulation }(\mathrm{C} 13)\end{array}$ & $\begin{array}{l}\text { The facilitation of access to information on art } \\
\text { licensing. }\end{array}$ & $\begin{array}{l}\text { Chen et al. [13] \& } \\
\text { Hsiang et al. [14] }\end{array}$ \\
\hline Value added to products (A2) & $\begin{array}{l}\text { The capability of cultural and creative goods to create } \\
\text { added value through art and culture licensing. }\end{array}$ & Experts \\
\hline $\begin{array}{l}\text { Product differentiation capability } \\
\text { (C21) }\end{array}$ & $\begin{array}{l}\text { Art-licensed products can be differentiated in the } \\
\text { market and are different from other products (a more } \\
\text { distinctive market differentiation or product } \\
\text { positioning indicates higher value). }\end{array}$ & $\mathrm{Lu}[34]$ \\
\hline Product topicality (C22) & $\begin{array}{l}\text { The topicality of art-licensed goods (a higher } \\
\text { topicality indicates more attention from consumers } \\
\text { and a higher value). }\end{array}$ & Experts \\
\hline $\begin{array}{l}\text { The ability of products to lead the } \\
\text { trend (C23) }\end{array}$ & $\begin{array}{l}\text { The ability of art-licensed goods to lead the trend (a } \\
\text { better capability indicates a higher value). }\end{array}$ & Experts \\
\hline $\begin{array}{l}\text { Organizational capability of } \\
\text { value-added manufacturers (A3) }\end{array}$ & $\begin{array}{l}\text { The organizational capability of value-added } \\
\text { manufacturers, which include its tangible and } \\
\text { intangible capabilities. }\end{array}$ & Experts \\
\hline Creative design capability (C31) & $\begin{array}{l}\text { The creative design capability of value-added } \\
\text { manufacturers. }\end{array}$ & Chiu [18] \\
\hline $\begin{array}{l}\text { Management and marketing } \\
\text { personnel (C32) }\end{array}$ & $\begin{array}{l}\text { Whether value-added manufacturers have enough } \\
\text { management and marketing personnel to create } \\
\text { business performance for the company. }\end{array}$ & $\begin{array}{l}\text { Chiu [18], Su [35], \& } \\
\text { Yang [36] }\end{array}$ \\
\hline Market mastery (C33) & $\begin{array}{l}\text { The extent to which value-added companies } \\
\text { understand market trends. }\end{array}$ & $\mathrm{Lu}[34]$ \\
\hline $\begin{array}{l}\text { Cross-industry integration } \\
\text { capability (C34) }\end{array}$ & $\begin{array}{l}\text { The capability of an enterprise to use different } \\
\text { materials and cooperate with different companies to } \\
\text { gain a competitive advantage. }\end{array}$ & Hua [37] \\
\hline $\begin{array}{l}\text { Internationalization capability } \\
\text { (C35) }\end{array}$ & $\begin{array}{l}\text { The capability of a value-added manufacturer to } \\
\text { expand its operations beyond the domestic market. }\end{array}$ & Experts, Liu [5], \& Su [35] \\
\hline
\end{tabular}

This questionnaire was distributed to manufacturers who had licensing partnerships with the National Palace Museum. Interviews and search results showed that the only a few manufacturers had a partnership with the National Palace Museum. Additionally, the list of cooperating manufacturers could not be obtained through public data, but only from newspapers, magazines, or interviews. This led to a situation in which we only obtained the cooperation of 15 manufacturers with the National Palace Museum. We sent out 15 questionnaires and received 11 responses, of which two were invalid and two were not used. The reason is that the manufacturers did not have a partnership with the National Palace Museum. Therefore, seven questionnaires were ultimately used. If the respondent assessed more than two licensing models, the respondent was considered as the sample for both models. After repeated calculation of the sample, 10 valid samples were obtained, out of which three were commissioned, 5 were brand-licensed, and 2 were image-licensed.

Thus, the analysis results were divided into four groups, namely the commissioned production group, brand licensing group, image licensing group, and the comprehensive group.

\subsection{Analysis of Relative Importance of Aspects and Criteria}

According to the calculation results, each group's recognized aspects and criterion weights can be obtained, as shown in Table 4, and analyzed as follows. Table 4 implies that the weight value of 
the "market environment" in the comprehensive group was the highest, indicating that value-added manufacturers attached great importance to the maturity of the market environment when considering the licensing model. In terms of importance, both the brand licensing group and image licensing group considered the "market environment" to be the most important, whereas the commissioned production group considered the "value added to products" to be the most important.

Table 4. Weights of aspect and criterion for each group.

\begin{tabular}{|c|c|c|c|c|c|}
\hline & Group & Comprehensive & $\begin{array}{l}\text { Commissioned } \\
\text { Production }\end{array}$ & $\begin{array}{c}\text { Brand } \\
\text { Licensing }\end{array}$ & $\begin{array}{c}\text { Image } \\
\text { Licensing }\end{array}$ \\
\hline Aspect/Criterion & & Weight (Rank) & Weight (Rank) & Weight (Rank) & Weight (Rank) \\
\hline A1 & Market environment & $0.84(1)$ & $0.93(2)$ & $0.82(1)$ & $0.85(1)$ \\
\hline A2 & Value added to products & $0.83(2)$ & $0.97(1)$ & $0.78(2)$ & $0.85(1)$ \\
\hline A3 & $\begin{array}{c}\text { Organizational } \\
\text { capability of } \\
\text { value-added } \\
\text { manufacturers }\end{array}$ & $0.70(3)$ & $0.67(3)$ & $0.78(2)$ & $0.70(2)$ \\
\hline $\mathrm{C} 11$ & Consumer demand & $0.83(2)$ & $0.97(1)$ & $0.76(2)$ & $0.75(2)$ \\
\hline $\mathrm{C} 12$ & $\begin{array}{l}\text { Protection of intellectual } \\
\text { property rights }\end{array}$ & $0.87(1)$ & $0.90(2)$ & $0.88(1)$ & $0.95(1)$ \\
\hline $\mathrm{C} 13$ & $\begin{array}{c}\text { Facilitation of } \\
\text { information circulation }\end{array}$ & $0.77(3)$ & $0.83(3)$ & $0.74(3)$ & $0.95(1)$ \\
\hline $\mathrm{C} 21$ & $\begin{array}{c}\text { Product differentiation } \\
\text { capability }\end{array}$ & $0.90(1)$ & $0.97(2)$ & $0.86(1)$ & $0.85(1)$ \\
\hline $\mathrm{C} 22$ & Product topicality & $0.84(3)$ & $0.97(2)$ & $0.78(3)$ & $0.80(2)$ \\
\hline $\mathrm{C} 23$ & $\begin{array}{l}\text { The ability of products to } \\
\text { lead the trend }\end{array}$ & $0.87(2)$ & $1.00(1)$ & $0.82(2)$ & $0.80(2)$ \\
\hline $\mathrm{C} 31$ & $\begin{array}{l}\text { Creative design } \\
\text { capability }\end{array}$ & $0.91(1)$ & $0.93(1)$ & $0.92(1)$ & $0.95(2)$ \\
\hline $\mathrm{C} 32$ & $\begin{array}{l}\text { Management and } \\
\text { marketing personnel }\end{array}$ & $0.76(4)$ & $0.60(3)$ & $0.88(2)$ & $1.00(1)$ \\
\hline $\mathrm{C} 33$ & Market mastery & $0.86(2)$ & $0.90(2)$ & $0.84(3)$ & $0.95(2)$ \\
\hline $\mathrm{C} 34$ & $\begin{array}{c}\text { Cross-industry } \\
\text { integration capability }\end{array}$ & $0.84(3)$ & $0.93(1)$ & $0.82(4)$ & $0.75(4)$ \\
\hline $\mathrm{C} 35$ & $\begin{array}{c}\text { Internationalization } \\
\text { capability }\end{array}$ & $0.74(5)$ & $0.60(3)$ & $0.88(2)$ & $0.85(3)$ \\
\hline
\end{tabular}

The comprehensive group assigned the highest weight to the "market environment" aspect. With respect to criteria under each aspect, "protection of intellectual property rights," "product differentiation capability," and "creative design capability" were deemed relatively important.

The commissioned production group assigned the highest weight to "value added to products." As for the criteria under each aspect, "consumer demand," "the ability of products to lead the trend," and "management and marketing personnel" were deemed relatively important.

The brand licensing group assigned the highest weight to "market environment." With regard to the criteria under each aspect, "protection of intellectual property rights," "product differentiation capability," and "creative design capability" were deemed relatively important.

The image licensing group assigned the highest weight to "market environment" and "value added to products." As for the criteria under each aspect, "protection of intellectual property rights," "facilitation of information circulation," "product differentiation capability," and "management and marketing personnel" were deemed relatively important. 


\subsection{Evaluation of Overall Performance Values}

The results were calculated according to the $\lambda$-fuzzy measure and Choquet integral. The $\lambda$ values were shown in Table 5 . The $\lambda$ values of the target and aspect for each group were less than 0 , suggesting a substitutive effect between the aspects and the criteria within the aspects. Therefore, it is necessary to enhance the performance of the criteria within the aspects valued by each group to improve the performance value of those aspects. The market environment is the pivotal aspect in the models of commissioned production and brand licensing viewed, whereas value added to products is the pivotal aspect in the image licensing model.

Table 5. $\lambda$ values of the target and aspect corresponded for each group.

\begin{tabular}{ccccccccc}
\hline \multirow{2}{*}{$\begin{array}{c}\text { Target and } \\
\text { Aspect }\end{array}$} & \multicolumn{2}{c}{ Comprehensive } & \multicolumn{2}{c}{ Commissioned Production } & \multicolumn{2}{c}{ Brand Licensing } & \multicolumn{2}{c}{ Image Licensing } \\
\cline { 2 - 9 } & $\lambda$ Value & Rank & $\lambda$ Value & Rank & $\lambda$ Value & Rank & $\lambda$ Value & Rank \\
\hline$\lambda$ & -0.99088 & & -0.99928 & & -0.99026 & & -0.99254 & \\
$\lambda \mathrm{A} 1$ & -0.99449 & 1 & -0.99948 & 1 & -0.99165 & 1 & -0.99936 & 2 \\
$\lambda \mathrm{A} 2$ & -0.99782 & 2 & -1.00000 & 3 & -0.99397 & 2 & -0.99345 & 1 \\
$\lambda \mathrm{A} 3$ & -0.99987 & 3 & -0.99992 & 2 & -0.99997 & 3 & -1.00000 & 3 \\
\hline
\end{tabular}

This section aims to investigate whether the overall performance values of the three licensing models vary for different groups. The overall performance values were calculated using the Choquet integral and are shown in Table 6.

Table 6. Overall performance values across groups.

\begin{tabular}{cccccccccccccc}
\hline Group & \multicolumn{3}{c}{ Comprehensive } & \multicolumn{3}{c}{$\begin{array}{c}\text { Commissioned } \\
\text { Production }\end{array}$} & \multicolumn{3}{c}{ Brand Licensing } & \multicolumn{3}{c}{ Image Licensing } \\
\hline Licensing Model & M1 & M2 & M3 & M1 & M2 & M3 & M1 & M2 & M3 & M1 & M2 & M3 \\
\hline $\begin{array}{c}\text { Overall performance } \\
\text { value (rank) }\end{array}$ & 78.63 & 82.36 & 75.48 & 86.95 & 90.71 & 81.33 & 78.13 & 80.98 & 74.30 & 73.93 & 85.42 & 81.07 \\
& $(2)$ & $(1)$ & $(3)$ & $(2)$ & $(1)$ & $(3)$ & $(2)$ & $(1)$ & $(3)$ & $(3)$ & $(1)$ & $(2)$ \\
\hline
\end{tabular}

In the comprehensive group, commissioned production group, and brand licensing group, the brand licensing model (M2) was found to be the best, followed by the commissioned production model (M1) and the image licensing model (M3). In the image licensing group, the brand licensing model was considered the best, followed by image licensing, and commissioned production. The performance values of 11 criteria are shown in Table 7. 
Table 7. Performance values of criteria in three licensing models for each group.

\begin{tabular}{|c|c|c|c|c|c|c|c|c|c|}
\hline \multirow{2}{*}{$\begin{array}{c}\text { Licensing Model } \\
\text { Group }\end{array}$} & \multicolumn{3}{|c|}{ M1 } & \multicolumn{3}{|c|}{ M2 } & \multicolumn{3}{|c|}{ M3 } \\
\hline & $\begin{array}{l}\text { Commissioned } \\
\text { Production }\end{array}$ & $\begin{array}{c}\text { Brand } \\
\text { Licensing }\end{array}$ & $\begin{array}{l}\text { Image } \\
\text { Licensing }\end{array}$ & $\begin{array}{l}\text { Commissioned } \\
\text { Production }\end{array}$ & $\begin{array}{c}\text { Brand } \\
\text { Licensing }\end{array}$ & $\begin{array}{c}\text { Image } \\
\text { Licensing }\end{array}$ & $\begin{array}{l}\text { Commissioned } \\
\text { Production }\end{array}$ & $\begin{array}{c}\text { Brand } \\
\text { Licensing }\end{array}$ & $\begin{array}{c}\text { Image } \\
\text { Licensing }\end{array}$ \\
\hline C11 & 80 & 82 & 79 & 80 & 87 & 93 & 76 & 77 & 86 \\
\hline C12 & 82 & 54 & 67 & 77 & 51 & 73 & 82 & 60 & 73 \\
\hline C13 & 84 & 78 & 66 & 79 & 70 & 66 & 79 & 70 & 66 \\
\hline C21 & 87 & 64 & 53 & 82 & 66 & 73 & 77 & 62 & 73 \\
\hline $\mathrm{C} 22$ & 87 & 67 & 53 & 91 & 75 & 66 & 77 & 72 & 66 \\
\hline $\mathrm{C} 23$ & 87 & 52 & 39 & 91 & 75 & 66 & 77 & 65 & 73 \\
\hline C31 & 86 & 62 & 53 & 82 & 72 & 66 & 77 & 57 & 66 \\
\hline C 32 & 86 & 60 & 53 & 82 & 69 & 66 & 77 & 73 & 66 \\
\hline C33 & 86 & 74 & 66 & 82 & 71 & 53 & 77 & 71 & 53 \\
\hline C34 & 86 & 64 & 66 & 82 & 76 & 60 & 77 & 67 & 60 \\
\hline C35 & 86 & 52 & 53 & 82 & 78 & 66 & 77 & 69 & 66 \\
\hline
\end{tabular}




\subsection{Importance-Performance Analysis}

This section aims to analyze whether the performance of each group, in terms of the aspects and criteria, are consistent with the importance assigned to them. Additionally, it seeks to explore whether the reinforcement of different key criteria can improve performance values under different licensing schemes. According to results of weight and performance values, we use the importance-performance analysis (IPA) to demonstrate the three licensing models' evaluation by specific group, as shown in Figures 3-5. This study is based on the actual experience of different expert groups on individual licensing models as a basis for evaluating these three models. Therefore, we use the experts of the commissioned production group to assess the performance of the commissioned production model. Furthermore, we assess the performance of brand licensing models using the experts of the brand licensing group. Finally, we assess the performance of the image licensing model using the experts of the image licensing group.

\section{Commissioned Production Model}

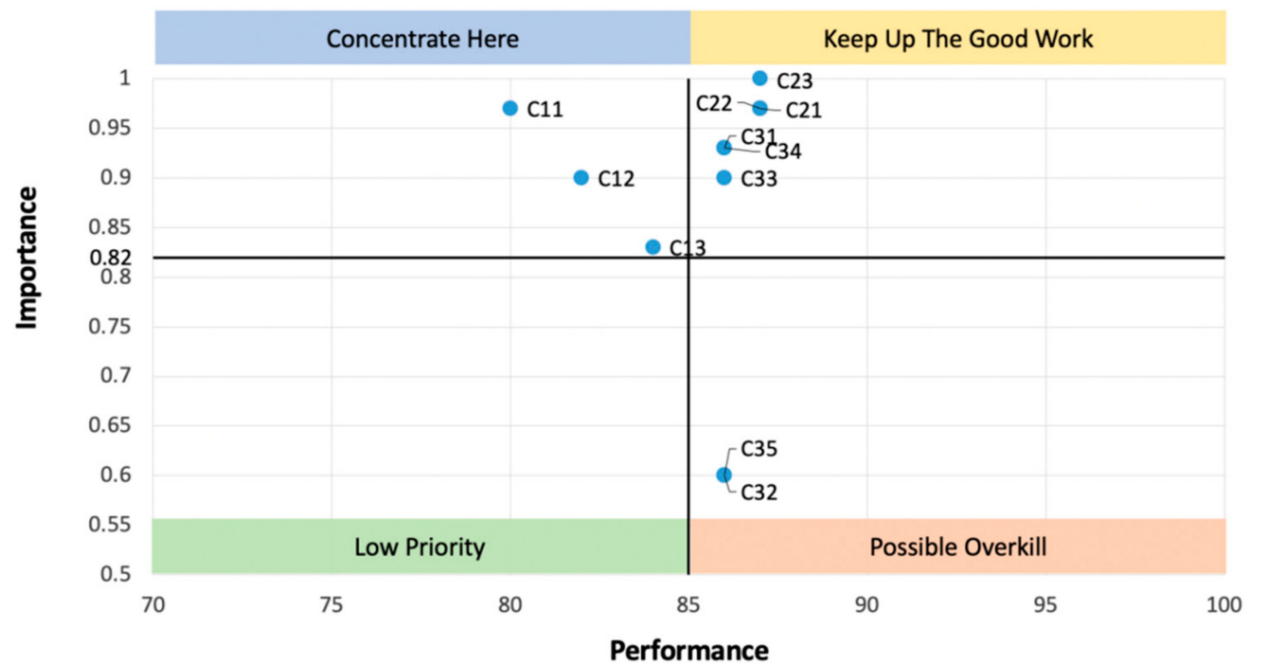

Figure 3. Importance-Performance Grid of Commissioned production model.

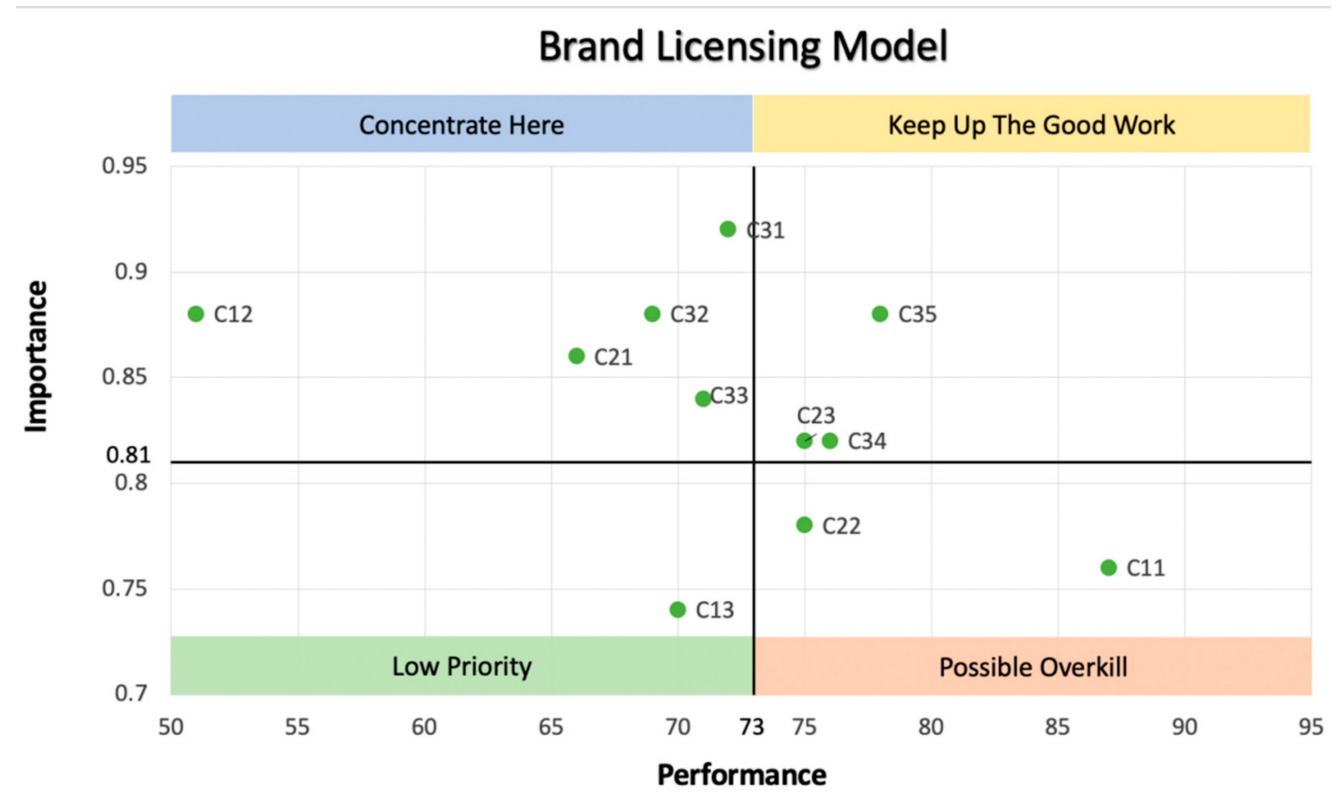

Figure 4. Importance-Performance Grid of Brand licensing model. 
Image Licensing Model

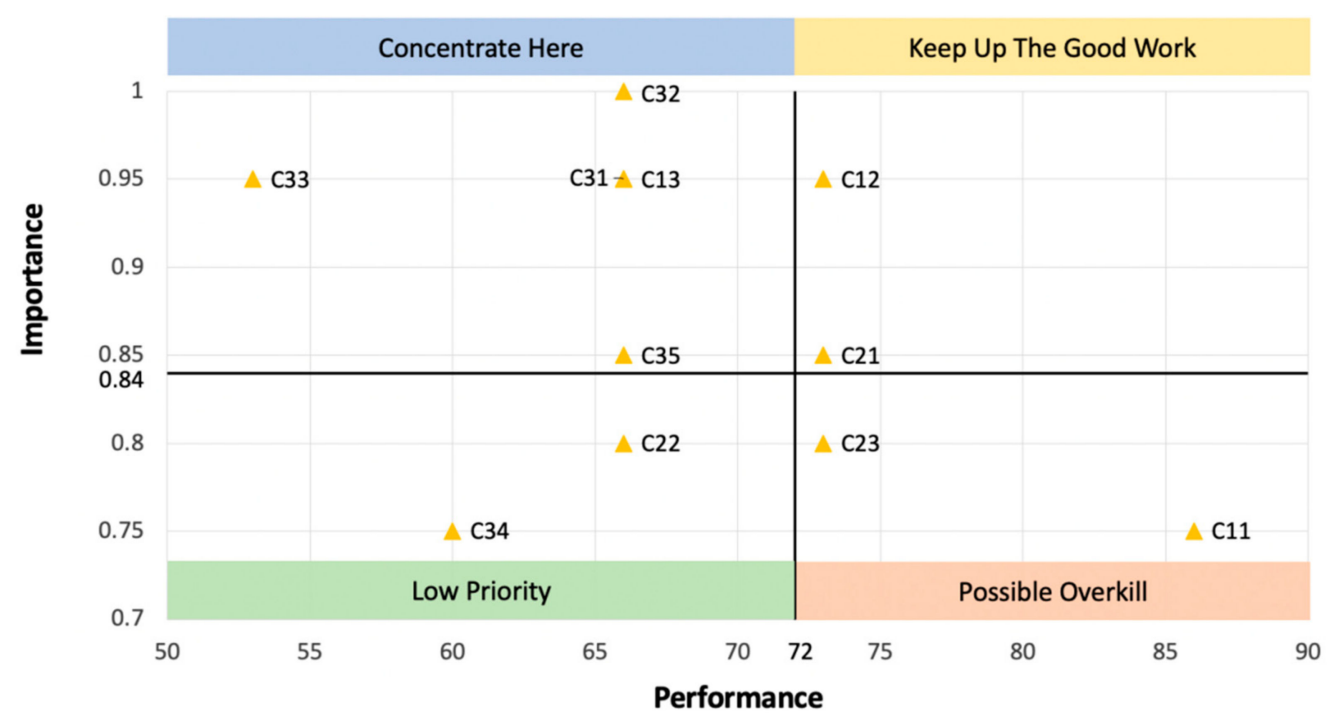

Figure 5. Importance-Performance Grid of Image licensing model.

The quadrant labels suggest that performance should be increased for some attributes ("Concentrate Here"), while reduced for others ("Possible Overkill") and maintained for the remainder ("Keep up the Good Work" and "Low Priority") [38].

\subsubsection{Commissioned Production Model}

According to discussions of the experts, they all agreed to use 85 as performance and 0.82 as importance thresholds. The C11 (Consumer demand), C12 (Protection of intellectual property rights) and C13 (Facilitation of information circulation) are in the quadrant of "Concentrate Here".

These experts indicate that "Consumer demand", "Protection of intellectual property rights" and "Facilitation of information circulation" is significant in the commissioned production model, but their performance value is the worst. Their performance value can be improved if these criteria are reinforced. These criteria all belong to aspect of "market environment". This makes sense, because this licensing model focuses on production but not marketing. If manufacturers want to develop their brands in the future, they need to focus on the cultivation of marketing capabilities.

The majority of criteria are in the "Keep up the Good Work" quadrant. In the commissioned manufacturing industry, manufacturers can continue to maintain their good performance in product value-added creation and organizational management capabilities.

\subsubsection{Brand Licensing Model}

According to discussions of the experts, they all agreed to use 73 as performance and 0.81 as importance thresholds. The C12 (Protection of intellectual property rights), C21 (Product differentiation capability), C31 (Creative design capability), C32 (Management and marketing personnel) and C33 (Market mastery) are in the quadrant of "Concentrate Here". These experts indicate that "Protection of intellectual property rights", "Product differentiation capability", "Creative design capability", "Management and marketing personnel" and "Market mastery" are highly important in brand licensing model, but their performance values are the worst. Their performance values can be improved if these criteria are reinforced. Three criteria belong to the aspect of "Organizational capability of value-added manufacturers". 


\subsubsection{Image Licensing Model}

According to discussions of the experts, they all agreed to use 72 as performance and 0.84 as importance thresholds. The C13 (Facilitation of information circulation), C31 (Creative design capability), C32 (Management and marketing personnel), C33 (Market mastery) and C35 (Internationalization capability) are in the dimension of "Concentrate Here". These experts indicate that "Facilitation of information circulation", "Creative design capability", "Management and marketing personnel", "Market mastery" and "Internationalization capability" are highly important in the image licensing model, but their performance values are the worst. Their performance values can be improved if these criteria are reinforced. Four criteria belong to aspect of "Organizational capability of value-added manufacturers". This means that if we improve the organizational capability, the performance can be improved quickly.

\section{Discussion}

In the past, scholars' discussion of the licensing mode of art and culture mainly focused on qualitative research, from case interviews or focus group interviews, to knowing the licensing relationship between value-added manufacturers and the National Palace Museum, while the vague questionnaire used in this study was closer to the subjective perception of the respondents, to fuzzy measurement and the fuzzy integral, to exploring the interaction between the composition and norms, and to enhancing the overall performance or composition performance by enhancing the key composition or key criteria. Therefore, this study hopes to use a literature review combined with expert interviews to develop a more complete art licensing evaluation model, and use fuzzy measurement to find out whether the value-added manufacturers pay more attention to the key composition and guidelines. It can be instructive in developing artistic empowerment.

Because of the empirical case, we have three limitations in this study. The first one is sample limitation. As it is not easy to obtain the list of vendors cooperating with the National Palace Museum, it is impossible to collect complete information of value-added vendors, so the questionnaire data collected in this study is limited. Therefore, it cannot represent the views of all value-added manufacturers. The second one is alternative limitation. There are only three licensing models of the National Palace Museum. The final one is that the selection structure of this study for the licensing model is based on literature review and expert interviews, so the composition and criteria of the assessment will be different depending on the experience of the experts and the background of the study.

It was suggested that the management of the delegation of authority mechanism could be explored. At present, the National Palace Museum is still within the public sector, and there is no effective use of its digital collection resources, thus the establishment of both efficient and effective authorization management mechanisms, can effectively promote cooperation opportunities for the value-added manufacturers and the National Palace Museum.

Most of the members of cultural and creative companies come from artistic culture or artistic management backgrounds, so the management of creative talents has become an important topic for leaders. It is suggested that the human resources management system of cultural and creative companies can be explored, and the selection and management of appropriate talents can help cultural and creative companies to develop and retain talents.

\section{Conclusions}

In the comprehensive group, brand licensing group, and image licensing group, it was concluded that market environment was the prioritized consideration for the selection of licensing models. Thus, the addition of commercial value to digital collection should account for the soundness of the market environment. When manufacturers want to use images of cultural relics that are displayed at the National Palace Museum to produce cultural goods, they give priority to market orientation and 
the maturity of the industrial environment. Moreover, due to the fact that manufacturers that adopt brand licensing and image licensing are responsible for their own marketing channels and activities, they assume higher risks. Consequently, reducing market uncertainty is a major consideration. In the commissioned production group, value added to products is the most important aspect. According to the interviewed manufacturers, commissioned products are primarily sold at the National Palace Museum and the consumers are mainly tourists. The souvenirs tourists want to buy after visiting the museum have added cultural value, which is why the value added to these products is paramount.

With regard to the market environment aspect, the protection of intellectual property rights is of paramount importance to the comprehensive group, brand licensing group, and image licensing group. In the digital age, an inadequate protection of intellectual property rights can have a negative impact on the industry due to the low cost of copying. Since brand and image licensees sell their products under their own brand name, they can suffer significant losses if they are counterfeited by others, which thereby discourages them from investing manpower and money into creative work. Thus, the two groups attached great importance to the ownership of intellectual property rights. The manufacturers that are engaged in commissioned production can only imprint the brand of the National Palace Museum on their products and sell them through fixed marketing channels of the National Palace Museum. Therefore, they have a relatively poor understanding of intellectual property rights. For the brand licensing and image licensing groups, the market environment is a core aspect and the protection of intellectual property rights is a vital criterion. If this criterion can be improved, it will enhance the performance of value-added manufacturers in the licensing model of the National Palace Museum. For the commissioned production and brand licensing groups, the crucial criterion for the organizational capability of value-added manufacturers is creative design capability, which suggests that value-added manufacturers should possess creativity when following the art and culture licensing model. This echoes Chiu's inference that the most important resource for museums in terms of art licensing is organizational capability, within which the most valued factor is creativity [18].

In our study, each group believed that the adoption of brand licensing can achieve a better overall performance value. According to the interviewed manufacturers, brand licensing can increase the visibility of the company's brand by imprinting the brands of both the National Palace Museum and the company on products. This aligns with our finding that brand licensing has a better performance value. Through the literature review and interviews with experts and scholars in the cultural and creative industries, we developed a framework for art licensing evaluation. It can be used as reference for future cultural and creative companies to use the digital collection of the National Palace Museum as a commercial value-added application and grasp various evaluation factors, thereby facilitating the selection of art licensing schemes by value-added manufacturers. The $\lambda$-fuzzy measure enables us to identify any interaction between the aspects. The results showed that $\lambda<0$, which indicates a substitutive effect between the aspects. From the $\lambda$ values calculated through the $\lambda$-fuzzy measure and Choquet integral, the market environment was deemed to be the key aspect for commissioned production and brand licensing, whereas the value added to products was deemed to be the key aspect for the image licensing scheme. The performance value of the licensing scheme can be improved if the corresponding key aspect is reinforced.

For value-added manufacturers that adopt brand licensing models, they will consider how to express cultural connotations in creative ways for their products to make them different from other products, and create a topical combination of brand and art. For the value-added manufacturers that take the image licensing model, it must consider the planning of marketing channels in front of time; that is, if the manufacturers themselves do not have strong marketing channels and brands, they may face the risk of no market, even if the product quality is good enough. As for commissioned production groups, they think that the product value-added composition is the most important, because commissioned products have been mainly sold in the National Palace Museum, so that the production of products with cultural images and creative design is the main consideration. 
According to empirical results, value-added manufacturers in the brand licensing model have endeavored to obtain the better performance. However, for those brand licensing partners, the situations are more stringent, because the adopted brand licensing program for the cultural goods will also hang the National Palace Museum trademark. This leads to a situation in which the National Palace Museum should select their partners carefully. The palace authority mentioned that because the National Palace Museum is a public institution, the artistic images in the museum constitute semi-public wealth. This means that the museum welcomes value-added manufacturers to receive a grant of artistic authorization. Of course, those manufacturers that have significant defects could not be taken into account.

At present, there are fewer value-added manufacturers to adopt image licensing. The value-added manufacturers to be interviewed mentioned that this is because the image licensing manufacturers cannot hang up the trademark of the National Palace Museum and can only sell on their own marketing channels. As a result, if the manufacturers do not have a strong marketing channels and brands, it is difficult to attract the attention of consumers. Furthermore, the empirical results found that the image licensing groups pay special attention to the management of marketing capacity. Therefore, for small cultural and creative companies, when adopting image licensing model, they will face the impact on marketing channels and the brand.

As most of Taiwan's cultural and creative companies are small and medium-sized with limited resources and market demand uncertainty, this study suggests that they first adopt the method of commissioned production to reduce risk and test the market. To find the balance between art and commerce, because of the risk of commissioned products in trafficking channels, manufacturers must have creative design capabilities to increase the purchase intentions of consumers of cultural goods.

Based on the findings, we put forward the following five suggestions.

1. Adoption of an agent licensing approach

Currently, the National Palace Museum adopts a self-licensing approach to images of its cultural relics and uses a passive method to wait for manufacturers to apply. Therefore, if the Museum can follow the agent licensing method and select a good agent to derive commercial value from the cultural relics from its digital archive, a greater value-added application effect can be produced, the licensing information can be circulated more easily, and licensing channels can be more accessible.

2. Education and publicity of intellectual property rights

For the cultural and creative industries, the greatest value of a product comes from the creativity of the content it represents. Thus, the protection of intellectual property rights is paramount. Professor Hsia deems that the protection of intellectual property rights should not solely rely on laws and regulations. Instead, intellectual property rights education should also be highly-prioritized, so as to make the public aware of the need to resist counterfeits.

3. A team with management and creativity

In cultural and creative companies, creative designers are important, but management personnel are the key to the company's expansion. According to General Manager Su, in the process of value-added application of art and culture, the management team should understand art and culture, be familiar with management, know the market, and be good at marketing and packaging. This will ensure that they avoid the situation where the products are highly competitive but remain unsold due to a lack of expertise.

4. Supporting measures of relevant government laws

Since most cultural and creative companies in Taiwan are small and medium-sized enterprises, the government should establish relevant supporting systems, such as loans and promotion of international exhibitions, which will enable cultural and creative companies to have more resources for innovative research and development and will increase their international visibility. 
5. The role of leaders as creative integrators

In the art licensing industry, cultural and popular trends are triggered by the cultural creativity of creators. Leaders in the organization should serve as creative integrators to combine practice with creativity and avoid unbridled creativity.

Author Contributions: Conceptualization, Y.-J.C.; Methodology, Y.-C.H.; Formal Analysis, Y.-W.K. and C.-W.L.; Data curation, J.-J.D.; Writing-Original Draft Preparation, Y.-J.C.; Writing-Review \& Editing, Y.-J.C. All authors have read and agreed to the published version of the manuscript.

Funding: This research received no external funding.

Conflicts of Interest: The authors declare no conflict of interest.

\section{References}

1. Kuo, Y. Art Licensing and Industry Value Chain in Museums: A Case Study of the National Palace Museum. Master's Thesis, Department of Communication Management, Shih Hsin University, Taipei, Taiwan, 2007.

2. Howkins, J. Creative Economy: Good Ideas Turned into Good Business; Li, P., Ed.; Trans; Artco Yishu: Taipei, Taiwan, 2003.

3. Ministry of Culture. 2019 Taiwan Cultural E Creative Industries Annual Report; Ministry of Culture: Taipei, Taiwan, 2020.

4. Hesmondhalgh, D. Cultural Industries; Liao, P., Ed.; Trans; Weber Publication International: Taipei, Taiwan, 2006.

5. Liu, W. What Are Cultural and Creative Industries?-The Contemporary Significance of Cultural Industries. ARTCO Mon. 2003, 128, 42-45.

6. Huang, W.W. A Probe into the Current Situation of the Development of Cultural and Creative Industries. J. CAGST 2019, 310-320. [CrossRef]

7. Wu, S. The Industrialization of Cultural Creativity (Vol. I). ARTCO Mon. 2004, 136, 114-117.

8. Wu, S. The Industrialization of Cultural Creativity (Vol. II). ARTCO Mon. 2004, 137, 134-137.

9. Chen, H. Metadata and Digital Archives. Univ. Arch. 2001, 5, 2-11.

10. Chen, L.P. Challenges for Digital Collection Development in the New Millennium. Chung Hsing J. Humanit. 2007, 38, 397-413.

11. Tsai, S.T. The Challenges and Opportunities of Museum Digital Development: Digital Archive, Digital Museum, E-Learning, and Digital Content Industry. Technol. Mus. Rev. 2004, 8, 21-42.

12. Hsiang, C.; Chen, H.; Cheng, T. A Study of the Industrial Prospect of Digital Archives. In Proceedings of the Symposium on Non-Technical Fields of Digital Archives, Department of Industrial Technology, Ministry of Economic Affairs, Taipei, Taiwan, 5-6 September 2002; pp. 435-447.

13. Hsiang, J.; Chen, H.H.; Cheng, D.F.; Wei, Y.H. On the Application of Digital Archives. J. Libr. Inf. Stud. 2004, 2, 1-17.

14. Hsiang, C.; Chen, H.; Chen, C.; Kuo, C. A Study of Business Models in the Digital Archives Industry. J. Libr. Assoc. Repub. China 2005, 75, 63-67.

15. Fondo, L. Art Licensing Show Steady Growth: Licensors continue to focus on art for it longevity in the marketplace and its growth popularity-Special Report. Art Bus. News 2003, 30.

16. Bruno, S. When Art Meets Economy: A Case Study and Cultural Policy; Tsai, I., Lin, H., Eds.; Trans; Artco Yishu: Taipei, Taiwan, 2003.

17. Chou, H. Legal Protection and Art Licensing of Intellectual Property in Taiwan's Cultural and Creative Industries: A Case Study of the National Palace Museum. Master's Thesis, School of Intellectual Property, National Chengchi University, Taipei, Taiwan, 2007.

18. Chiu, Y. Art Licensing Strategies in Museums: An Analysis of Resource-Based Perspectives. Master's Thesis, Department of Information Management, Ming Chuan University, Taipei, Taiwan, 2006.

19. Tang, M.T.; Tzeng, G.H.; Wang, S.W. A Hierarchy Fuzzy MCDM Method for Studying Electronic Marketing Strategies in the Information Service Industry. J. Int. Inf. Manag. 1999, 8, 1-22.

20. Tsaur, S.H.; Chang, T.Y.; Yen, C.H. The Evaluation of Airline Service Quality by Fuzzy MCDM. Tour. Manag. 2002, 23, 107-115. 
21. Yildiz, A.; Yayla, A.Y. Application of Fuzzy TOPSIS and Generalized Choquet Integral Methods to Select the Best Supplier. Decis. Sci. Lett. 2017, 6, 137-150. [CrossRef]

22. Tseng, F.M.; Chiu, Y.J. Hierarchical Fuzzy Integral Stated Preference Method for Taiwan's Broadband Service Market. Omega Int. J. Manag. Sci. 2005, 33, 55-64. [CrossRef]

23. Lu, M.T.; Tsai, J.F.; Shen, S.P.; Lin, M.H.; Hu, Y.C. Estimating Sustainable Development Performance in the Electrical Wire and Cable Industry: Applying the Integrated Fuzzy MADM Approach. J. Clean. Prod. 2020, 277, 122440. [CrossRef]

24. Sugeno, M. Theory of Fuzzy Integrals and Its Applications. Ph.D. Thesis, Tokyo Institute of Technology, Tokyo, Japan, 1974.

25. Tseng, K.; Hsieh, C.; Huang, M. Fuzzy AHP and Non-additive Fuzzy Integration for Contractor Selection. J. Technol. Manag. 2007, 12, 29-54.

26. Wang, Z.; Klir, G.J. Fuzzy Measure Theory; Plenum Press: New York, NY, USA, 1992.

27. Wang, Z.; Leung, K.S.; Wang, J. A Genetic Algorithm for Determining Nonadditive Set Functions in Information Fusion. Fuzzy Sets Syst. 1999, 102, 463-469. [CrossRef]

28. Sugeno, M.; Narukawa, Y.; Murofushi, Y. Choquet Integral and Fuzzy Measures on Locally Compact Space. Fuzzy Sets Syst. 1998, 7, 205-211. [CrossRef]

29. Kuncheva, L.I. Fuzzy Classifier Design; Physica-Verlag: Heidelberg, Germany, 2000.

30. Hu, Y.C.; Chiu, Y.J.; Liao, Y.L.; Li, Q. A Fuzzy Similarity Measure for Collaborative Filtering Using Nonadditive Grey Relational Analysis. J. Syst. 2015, 27, 93-103.

31. Chiang, J.H. Choquct Fuzzy Integral-Based Hierarchical Networks for Decision Analysis. IEEE Trans. Fuzzy Syst. 1999, 7, 63-71. [CrossRef]

32. Caves, R. The Cultural and Creative Industries: Using Contracts to Meet Art and Commerce; Chong, H., Hsu, T., Eds.; Trans; Artco Yishu: Taipei, Taiwan, 2003.

33. Shang, A. Research on the Legal Issues on the Value-Added Application of Digital Archive. Master's Thesis, School of Intellectual Property, National Chengchi University, Taipei, Taiwan, 2004.

34. Lu, J. The Business and Marketing Strategies of the Art Licensing Industry. Master's Thesis, School of Institute of Technology and Innovation Management, National Chengchi University, Taipei, Taiwan, 2005.

35. Su, Y. A Study of Value Systems and Key Factors in the Digital Archives Industry. Master's Thesis, School of Business, National Taiwan University, Taipei, Taiwan, 2006.

36. Yang, C. A Study of the Creative Process of Innovative Teams: A Case Study of Performing Arts Troupe. Master's Thesis, School of Science and Technology Management, National Chengchi University, Taipei, Taiwan, 2003.

37. Hua, C. Culture + Creativity $=$ Wealth Ver. 2.0. In Empire and Culture; Empire Culture: Taipei, Taiwan, 2006.

38. Martilla, J.A.; James, J.C. Importance-Performance Analysis. J. Mark. 1977, 41, 13-17. [CrossRef]

Publisher's Note: MDPI stays neutral with regard to jurisdictional claims in published maps and institutional affiliations.

(C) 2020 by the authors. Licensee MDPI, Basel, Switzerland. This article is an open access article distributed under the terms and conditions of the Creative Commons Attribution (CC BY) license (http://creativecommons.org/licenses/by/4.0/). 